\title{
Darwin wasps: a new name heralds renewed efforts to unravel the evolutionary history of Ichneumonidae
}

\author{
Seraina Klopfstein ${ }^{1 \pm( \pm \infty}$, Bernardo F. Santos ${ }^{2 \oplus}$, Mark R. Shaw ${ }^{3(}$, Mabel Alvarado ${ }^{4(}$, \\ Andrew M. R. Bennett ${ }^{5}$, Davide Dal Pos ${ }^{6}{ }^{6}$, Madalene Giannotta ${ }^{7}$, Andres F. Herrera \\ Florez $^{8 \oplus}$, Dave Karlsson ${ }^{9 \oplus}$, Andrey I. Khalaim ${ }^{10 \oplus}$, Alessandro R. Lima ${ }^{11}$, István Mikó ${ }^{12}$, \\ llari E. Sääksjärvi ${ }^{13}$, So Shimizu ${ }^{14}$, Tamara Spasojevic ${ }^{2 \oplus}$, Simon van Noort ${ }^{15}$, Lars \\ Vilhelmsen $^{16 \oplus}$, Gavin R. Broad ${ }^{17(-)}$
}

${ }^{1}$ Natural History Museum Basel, BIO, Augustinergasse 2, 4051 Basel, Switzerland. ${ }^{2}$ Department of Entomology, National Museum of Natural History, 10th Street \& Constitution Ave. NW, Washington, DC 20560, USA. ${ }^{3}$ National Museums of Scotland, Chambers Street, Edinburgh EH1 1JF, U.K. ${ }^{4}$ Departamento de Entomología, Museo de Historia Natural, UNMSM. Av. Arenales 1256 Jesús María, Lima 14, Perú. ${ }^{5}$ Agriculture and Agri-Food Canada, Canadian National Collection of Insects, Arachnids and Nematodes, 960 Carling Avenue, Ottawa, Ontario, K1A OC6, Canada. ${ }^{6}$ Department of Biology, University of Central Florida, 4110 Libra Dr. Rm 442 , Orlando, FL 32816, USA. ${ }^{7}$ ACEBB, The University of Adelaide, Australia. ${ }^{8}$ Department of Biology, Ludwig-Maximilians-University of Munich, Germany. ${ }^{9}$ Station Linné, Ölands Skogsby, Färjestaden, Sweden. ${ }^{10}$ Zoological Institute of the Russian Academy of Sciences, St Petersburg, Russia; and Universidad Autonoma de Tamaulipas, Cd. Victoria, Mexico. ${ }^{11}$ Centro de Coleções Taxonômicas, Instituto de Ciências Biológicas, Universidade Federal de Minas Gerais, Brazil. ${ }^{12}$ UNH Collection of Insects and other Arthropods, University of New Hampshire, Durham, NH, USA. ${ }^{13}$ Biodiversity Unit, 20014 University of Turku, Finland. ${ }^{14}$ Laboratory of Insect Biodiversity and Ecosystem Science, Kobe University, Rokkodaicho 1-1, Nada, Kobe, Hyogo 657-8501, Japan. ${ }^{15}$ Research and Exhibitions Department, South African Museum, Iziko Museums of South Africa, P.O. Box 61, Cape Town, 8000, South Africa; and Department of Biological Sciences, University of Cape Town, Private Bag, Rondebosch, 7701, South Africa. ${ }^{16}$ Natural History Museum of Denmark, SCIENCE, University of Copenhagen, Universitetsparken 15, DK-2100, Denmark. ${ }^{17}$ Department of Life Sciences, the Natural History Museum, Cromwell Road, London SW7 5BD, U.K

拝=Corresponding author: seraina.klopfstein@bs.ch

Edited by: Daniell Rodrigo Rodrigues Fernandes

Received: October 11, 2019. Accepted: December 01, 2019. Published: December 08, 2019.

Abstract. The parasitoid wasp family Ichneumonidae is arguably one of the groups for which current knowledge lags most strongly behind their enormous diversity. In a five-day meeting in Basel (Switzerland) in June 2019, 22 researchers from 14 countries met to discuss the most important issues in ichneumonid research, including increasing the speed of species discovery, resolving higher-level relationships, and studying the radiation of these parasitoids onto various host groups through time. All agreed that it is time to advertise ichneumonid research more broadly and thereby attract young talents to this group for which specialists are sorely lacking, as well as increase public awareness about their exciting biology and ecological impact. In order to popularize the group, we here suggest a new vernacular name for the family, "Darwin wasps", to reflect the pivotal role they played in convincing Charles Darwin that not all of creation could have been created by a benevolent god. We hope that the name catches on, and that Darwin wasps start buzzing more loudly across all disciplines of biology.

Keywords: Alpha taxonomy, fossils, paleoentomology, parasitoid wasps, phylogenetics.

"I cannot persuade myself that a beneficent and omnipotent God would have designedly created the Ichneumonidae with the express intention of their feeding within the living bodies of caterpillars (...)" (Darwin 1860)

The insect family that so famously stirred skeptic thoughts in Darwin, the Ichneumonidae, is among the most species-rich branches of the tree of life. At the same time, it is one of the groups for which our knowledge most severely lags behind their actual diversity. The roughly 25,000 species described today (Yu et al. 2016) probably represent less than a quarter of their true richness, but reliable estimates are lacking, as is much of the most basic knowledge about their ecology, distribution and evolution (Quicke 2015). Ichneumonid wasps, with very few exceptions, attack the immature stages of holometabolous insects and spiders, eventually killing their hosts (Broad et al. 2018).
They thus fulfill an important role as regulators of insect populations, both in natural and semi-natural systems, making them promising agents for biological control - aspects that Darwin overlooked when using these wasps to make a point about the lack of evidence for a benevolent god.

\section{Darwin wasps - a new popular name for Ichneumonidae}

One way to popularize a hitherto poorly appreciated taxon is by coining a catchy vernacular name that should be meaningful both to scientists and to the general public. We suggest "Darwin wasps" as the new name for this family, which until now has been known in English only as "ichneumon wasps" or even "ichneumon flies". The new 
name is intended primarily in reference to Darwin's famous quote, but also to draw general attention to what is likely one of the largest adaptive radiations in the natural world. We are only just beginning to understand the extent of the manifold and sophisticated adaptations by Darwin wasps to finding, overpowering and manipulating their hosts, and research into speciation mechanisms is highly promising in this group, which probably contains more species than all vertebrates together

\section{Species-level taxonomy}

Much of our knowledge of ichneumonid diversity is based on the fauna of north temperate areas of the globe, but this is changing. Large-scale, intensive collecting efforts in, e.g., Brazil, Chile, Colombia, Costa Rica, Peru, Uganda and South Africa are revealing and characterizing a massive diversity of southern Darwin wasps. Still, we are only starting to understand the roles played by latitude, altitude and other environmental characteristics in shaping the abundance and distribution of these parasitoids across the globe (Quicke 2015). Species description rates are increasing for tropical countries, thus increasingly reflecting the geographic distribution of species richness. However, this seems to have been offset by the decline of large-scale monographic work, meaning that worldwide description rates have remained roughly stable (with a mean of 212 species per year since 1900; Yu et al. 2016) (Fig. 1). Species description rates need to increase substantially if we are to make any impact on the taxonomic deficit in a useful timeframe.

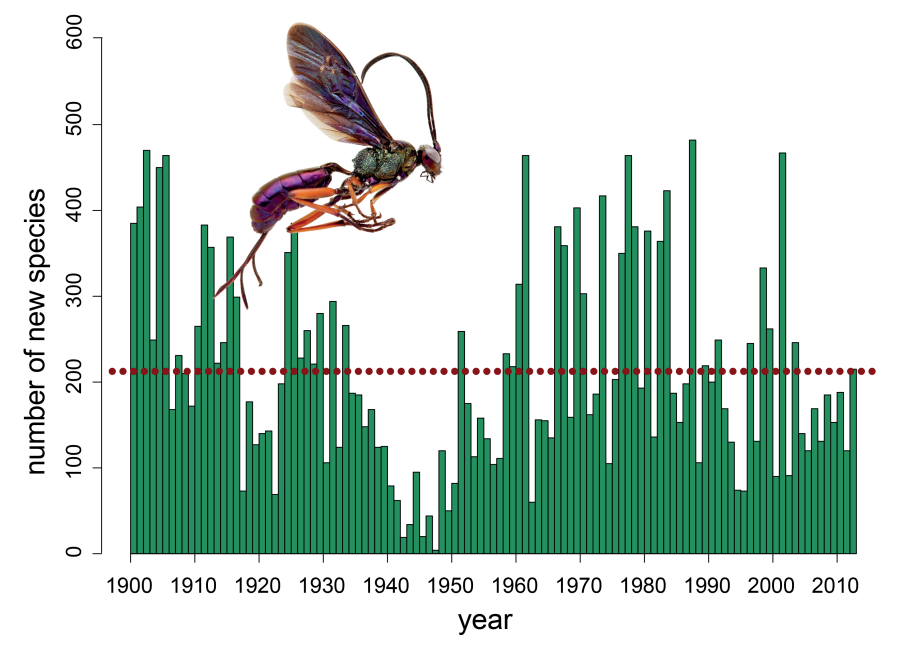

Figure 1. Annual totals of new species descriptions of Ichneumonidae. The dotted horizontal line represents the average of 212 species per year.

While there is a general knowledge of the broad host relations of most subfamilies and tribes of Darwin wasps (Broad et al. 2018), at genus and species level our knowledge of host range, behaviour and developmental biology is deplorably low (Shaw 1994). Some researchers make a commendable effort to combine taxonomic revisions with an assessment of the reliability of published host records and the reporting of new, confirmed host data (e.g., Broad \& Shaw 2016). We need to encourage such basic life history research, not least because it is becoming clear that there are many cryptic species differing in these respects, but also because important drivers for speciation will be found.

\section{Darwin wasp diversity in collections}

The specimen base for taxonomy, i.e., the raw resource for ichneumonologists, is scattered across many collections with no centralised database, and in many cases no way of accessing data. At the workshop, we started compiling a resource for the community, comprising collection-level descriptions of ichneumonid diversity and the nature of bulk samples in collections.

As examples of undescribed species richness, we performed a quick review of unidentified samples of Banchinae from Southern Hemisphere countries in a few collections and in the literature. For instance, San Marcos Museum (Peru) has 190 morphospecies of Banchinae, with only 20 of these described; Gauld (1984) noted 121 morphospecies of Banchinae in Australia, with only 25 of these described; and NHMUK holds samples of Atrophini (Banchinae) from 25 Afrotropical countries, seven of which have no published records of the tribe. Accessibility of this material is very heterogeneous. The pinned collections of named specimens are databased at the level of a species in a drawer. The unidentified, pinned specimens are poorly databased, although available to taxonomists. The bulk alcohol samples are mostly uncatalogued and unavailable, which is a significant impediment to taxonomic work on Darwin wasps.

Some institutions have much better records of their alcoholpreserved material, although the availability of large samples of Ichneumonidae, e.g., from Uganda and South Africa in Turku (Finland) and the Iziko South African Museum, Cape Town, South Africa, should be better publicized. It is clear that the most useful taxonomic revisions follow from large-scale, targeted collecting, although spot samples from the wider world fill in many blanks. Results of these efforts can be seen in numerous revisions from, in particular, groups in Turku (headed by Ilari Sääksjärvi) and Cape Town (headed by Simon van Noort). Huge progress in describing the Chinese fauna has also been made in recent years, particularly from Sheng Mao-Ling's group.

\section{New faunal works}

Henry Townes's series (1969-1971) of identification keys to all of the genera of Ichneumonidae (except Ichneumoninae and Hybrizontinae) remain essential references. However, these works are showing their age - modern identification keys, for example, need to be well illustrated. Monographs of North American and Costa Rican ichneumonid subfamilies essentially stopped with the deaths of Henry Townes, Gerd Heinrich, Clement Dasch and Ian Gauld (Heinrich 1978, Dasch 1992, Gauld et al. 2002). This is not to say that work has finished in the traditionally better-known Holarctic fauna. Seraina Klopfstein's (2014) revision of the Western Palaearctic Diplazontinae is a recent work tackling a medium-sized subfamily for the region, and Andrey Khalaim's works are adding up to a global revision of Tersilochinae (e.g., Khalaim 2017).

A consensus at the workshop was that keys to genera would be particularly useful at the regional level. Simon van Noort has been adding dichotomous and interactive keys to WaspWeb (van Noort 2019) for the Afrotropical Hymenoptera Initiative. As a community, we can work to publish keys to the genera of Afrotropical Ichneumonidae within a relatively short period of time. Simultaneously, there are ongoing efforts to produce keys to the genera of particular subfamilies (e.g., Ctenopelmatinae and Orthocentrinae), which can be broken down into regional keys. Much improved imaging technology, more intensive collections from around the world, and a better understanding of ichneumonid phylogeny mean the time is ripe for new generic keys and a revised classification, making the family more accessible to the next generations of entomologists.

\section{Assembling the ichneumonid tree}

To understand the diversity of life history traits, morphological characters and diversification patterns found in Darwin wasps, we need to place them in evolutionary context. Phylogenies have become a fundamental tool for evolutionary biology, transcending the goal of tracing species relationships to increasingly being used to study aspects of evolution, ecology, biogeography, functional morphology, and much more.

And yet, as with so many aspects of Darwin wasp research, progress in our knowledge on their evolutionary relationships has been regrettably slow. Most of the earlier, morphological phylogenetic studies focused on specific subfamilies or subgroups (e.g., Wahl 1993, Bennett 2001). Studies using molecular data did not become prevalent until recently. Most past studies have used data from a single locus (usually $28 \mathrm{~S}$ rRNA) and had weakly supported results (Belshaw et 
al. 1998). The work of Quicke et al. (2009), featuring "a thousand and one wasps", became a landmark on phylogenetic investigations with Ichneumonidae, providing for the first time a dense taxonomic sampling across the entire family. However, the results were poorly supported and sensitive to parameter choice.

More recently, multigene studies have so far mostly focused on specific subfamilies (e.g., Klopfstein et al. 2011 for Diplazontinae, Santos 2017 for Cryptinae). Investigations using multiple genes and focusing on a broader taxonomic scope have just started to get published (Klopfstein et al. 2019 for Pimpliformes; Bennett et al. 2019 for the family as a whole) and provide an encouraging signal that the scenario is about to change for ichneumonid systematics.

In spite of the sparse and fragmentary nature of past phylogenetic works, a few relatively solid points of consensus have emerged. First, the Xoridinae seem to be reliably the sister of all other Ichneumonidae. In addition, three major groups of subfamilies have been identified, though the limits of each one is subject to discussion: the Ophioniformes, Ichneumoniformes, and Pimpliformes. The relationships among and within these major groups are still far from well-defined, and the positions of several subfamilies, such as Orthopelmatinae and Labeninae, remain elusive (Quicke 2015).

The time is now ripe for a concerted effort to unravel the tree of life of ichneumonids and unlock its enormous potential to illuminate studies in ecology and evolution. Phylogenomic approaches have greatly decreased in cost and are increasingly being adopted by the entomological community. Various genomic approaches (e.g., transcriptomes, exon enrichment, etc.) have different strengths and weaknesses and can be used in parallel, providing a desirable crossvalidation of the results. In general, target enrichment approaches such as ultraconserved elements (UCEs; Faircloth et al. 2012) provide a reliable and cost-effective avenue for large-scale sequencing for hyperdiverse groups. Target genomic loci with relatively short sequences can be captured and sequenced even for decades-old museum specimens. Combined with massive parallel sequencing, these approaches represent a leap of one to two orders of magnitude in the volume of data when compared to traditional molecular phylogenies, potentially leading to much more robust results.

In an ongoing, collaborative effort to investigate the phylogeny of Ichneumonidae, we have assembled a UCE dataset including roughly 600 genera from all 42 subfamilies (Broad et al. 2018). The preliminary results, which we discussed in detail at the meeting, corroborate some of the major points of consensus in our current knowledge, while also providing an unprecedented level of detail and robustness in our understanding of the ichneumonid tree of life. However, much remains to be done; for example, historically poorly studied groups such as Ichneumoninae and Ctenopelmatinae are still underrepresented in the UCE tree due to difficulty in obtaining reliably identified specimens that can yield usable DNA. Future plans include expanding this tree to include a majority of ichneumonid genera; to use the phylogeny to investigate transitions in host use and other biological traits; and to understand the tempo and mode of ichneumonid diversification by putting their phylogeny in a temporal context.

\section{The ichneumonid fossil record}

The main source of information for dating phylogenetic trees is contained in the fossils of a group. The fossil record of Darwin wasps dates back to the early Cretaceous or even late Jurassic (e.g., Kopylov 2009), but like the extant diversity of the family, it is very poorly studied. Only 277 species have been described to date (EDNA database; Mitchell 2013), 75\% of which by just eight authors, and while the known Mesozoic fossils have mostly been examined in detail, there are still many hundreds of unstudied Cenozoic specimens present in fossil collections. In addition, a large portion of the described species was studied only before Townes published his seminal volumes on ichneumonid taxonomy (Townes 1969 and subsequent volumes); their classification is thus in dire need of revision (Fig. 2).

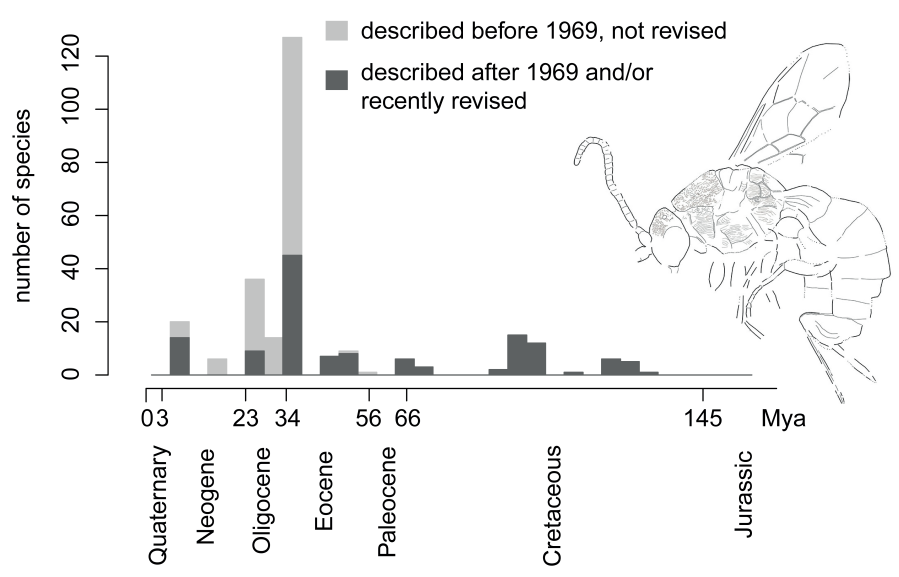

Figure 2. Number of fossil species of Darwin wasps described or revised in the latest half-century versus those described before the modern classification of the group. Fossil ages are given as minimum estimates of the stratum ages.

Three main factors complicate the interpretation and classification of ichneumonid fossils: high levels of homoplasy caused by parallel adaptations to the same hosts and/or host ecologies; a lack of knowledge of ichneumonid taphonomy, i.e., of the way their bodies fossilize; and finally the current absence of a robust age estimate of the crown group that would guide classification through knowledge of which higher taxa had already appeared at a particular time. None of these issues are insurmountable: homoplasies can be identified by morphological phylogenetics based on careful character concepts; taphonomy can be tackled at least to some extent experimentally; and a first age estimate for the pimpliform subfamilies based on total-evidence dating will soon become available. At the meeting, we decided to undertake a collaborative effort to date the entire tree of Darwin wasps by combining molecular data with a large morphological matrix, a project that will also require intensified research into the ichneumonid fossil record.

\section{The future of Darwin wasp research}

There was consensus during the conference that we need to increase collaboration and data sharing in order to boost research into every aspect of ichneumonid diversity and evolution. As a first step, we have made the program of the meeting, abstracts and presentations available online (https://zenodo.org/communities/ ichn_meeting_2019). Research priorities for the next five years are: (1) publishing the first time-calibrated, comprehensive phylogeny for the group based on genomic data; (2) producing synthetic regional works for the family as a whole; the obvious starting point is the ongoing monograph of Afrotropical Ichneumonidae led by Simon van Noort; (3) advancing the understanding of global patterns of ichneumonid diversity, with an emphasis on long-term studies of the tropical fauna.

In terms of research infrastructure, five points are particularly urgent: (1) increasing our efforts to collect Darwin wasps, especially through long-term inventories and in threatened and undersampled habitats and regions; (2) making the collected material available to the entire community through proper curation and specimen exchanges; (3) developing a platform for storage and sharing of ichneumonid literature, especially old and rare works; (4) integrating the most recent account of morphological terminology (Broad et al. 2018) into the Hymenoptera Anatomy Ontology; and last but not least, (5) establishing an alternative to the ichneumonoid catalogue and database, Taxapad, the demise of which has been a major blow for ichneumonid research.

Stepping up to the challenge of understanding the diversity and evolution of Darwin wasps will require creating new research tools, persuading researchers to foster collaborations, and handle ever larger datasets with the express intention of elucidating diverse research questions. We expect that a revived interest in Darwin wasps will lead to a more beneficent research program and to exciting discoveries in this fascinating group of insects. 


\section{Authors' Contribution}

SK, BFS, GRB and MRS prepared the first version of the manuscript. All authors took part in the conference and workshop, where we discussed the ideas that cumulated in this work. All authors commented on the manuscript and added valuable information from their own collections.

\section{References}

Belshaw, R.; Fitton, M.; Herniou, E.; Gimeno, C.; Quicke, D. L. J. (1998). A phylogenetic reconstruction of the Ichneumonoidea (Hymenoptera) based on the D2 variable region of $28 \mathrm{~S}$ ribosomal RNA. Systematic Entomology, 23: 109-123. doi: 10.1046/j.13653113.1998.00046.x

Bennett, A. M. R. (2001). Phylogeny of Agriotypinae (Hymenoptera: Ichneumonidae), with comments on the subfamily relationships of the basal Ichneumonidae. Systematic Entomology, 26: 329-356. doi: 10.1111/j.1365-3113.1983.tb00477.x

Bennett, A. M. R.; Cardinal, S.; Gauld, I. D.; Wahl, D. B. (2019). Phylogeny of the subfamilies of Ichneumonidae (Hymenoptera). Journal of Hymenoptera Research, 71: 1-156. doi: 10.3897/jhr.71.32375

Broad, G. R.; Shaw, M. R. (2016). The British species of Enicospilus (Hymenoptera: Ichneumonidae: Ophioninae). European Journal of Taxonomy, 187: 1-31. doi: 10.5852/ejt.2016.187

Broad, G. R.; Shaw, M. R.; Fitton, M. G. (2018). Ichneumonid wasps (Hymenoptera: Ichneumonidae): their classification and biology. Handbooks for the Identification of British Insects, 7(12): 1-418.

Darwin, C. (1860). Letter no. 2814, to Asa Gray. Darwin Correspondence Project, https://www.darwinproject.ac.uk/letter/DCP-LETT-2814. $\mathrm{xml}$.

Dasch, C. E. (1992). The ichneumon-flies of America north of Mexico: Part 12. Subfamilies Microleptinae, Helictinae, Cyllocerinae and Oxytorinae (Hymenoptera: Ichneumonidae). Memoirs of the American Entomological Institute, 52: 1-470.

Faircloth, B. C.; McCormack, J. E.; Crawford, N. G.; Harvey, M. G.; Brumfield, R. T.; Glenn, T. C. (2012). Ultraconserved Elements Anchor Thousands of Genetic Markers Spanning Multiple Evolutionary Timescales. Systematic Biology, 61: 717-726. doi: 10.1093/sysbio/sys004

Gauld, I. D. (1984). An introduction to the Ichneumonidae of Australia. London: British Museum (Natural History).

Gauld, I. D.; Sithole, R.; Gómez, J. U.; Godoy, C. (2002). The Ichneumonidae of Costa Rica, 4. Memoirs of the American Entomological Institute, 66: 1-768.

Heinrich, G. H. (1978). Synopsis of Nearctic Ichneumoninae Stenopneusticae, with particular reference to the northeastern region (Hymenoptera). Supplement 6. Naturaliste Canadien, 105: 159-168.

Khalaim, A. I. (2017). Tersilochinae (Hymenoptera: Ichneumonidae) of Vietnam, part 2: genus Barycnemis Förster, 1869. Proceedings of the Zoological Institute RAS, 321: 371-376.

Klopfstein, S. (2014). Revision of the Western Palaearctic Diplazontinae (Hymenoptera, Ichneumonidae). Zootaxa, 3801: 1-143. doi: 10.11646/zootaxa.3801.1.1

Klopfstein, S.; Quicke, D. L. J.; Kropf, C.; Frick, H. (2011). Molecular and morphological phylogeny of Diplazontinae (Hymenoptera, Ichneumonidae). Zoologica Scripta, 40: 379-402. doi: 10.1111/j.1463-6409.2011.00481.x

Klopfstein, S.; Langille, B.; Spasojevic, T.; Broad, G. R.; Cooper, S. J. B.; Austin, A. D.; Niehuis, O. (2019). Hybrid capture data unravel a rapid radiation of pimpliform parasitoid wasps (Hymenoptera: Ichneumonidae: Pimpliformes). Systematic Entomology, 44: 361 383. doi: 10.1111/syen.12333

Kopylov, D. S. (2009). A new subfamily of ichneumons from the lower Cretaceous of Transbaikalia and Mongolia (Insecta: Hymenoptera: Ichneumonidae). Paleontologicheskii Zhurnal, 1: 76-85. doi: 10.1134/s0031030109010092

Mitchell, A. A. (2013). EDNA, the fossil insect database. http://edna.palass-hosting.org. Accessed on: 26.ix.2019.

Quicke, D. L. J. (2015). The braconid and ichneumonid parasitoid wasps: biology, systematics, evolution and ecology. Chichester: John Wiley \& Sons, Ltd.

Quicke, D. L. J.; Laurenne, N. M.; Fitton, M. G.; Broad, G. R. (2009). A thousand and one wasps: a $28 \mathrm{~S}$ and morphological phylogeny of the Ichneumonidae (Insecta: Hymenoptera) with an investigation into alignment parameter space and elision. Journal of Natural History, 43: 1305-1421. doi: 10.1080/00222930902807783

Santos, B. F. (2017). Phylogeny and reclassification of Cryptini (Hymenoptera, Ichneumonidae, Cryptinae), with implications for ichneumonid higher-level classification. Systematic Entomology, 42: 650-676. doi: 10.1111/syen.12238

Shaw, M. R. (1994). Parasitoid host ranges. In: Hawkins, B. A.; Sheehan, W. (Eds.), Parasitoid Community Ecology, pp. 111-144. Oxford: Oxford University Press.

Townes, H. K. (1969). The genera of Ichneumonidae, Part 1. Memoirs of the American Entomological Institute, 11: 1-300.

Van Noort, S. (2019). WaspWeb: Hymenoptera of the Afrotropical region. http://www.waspweb.org. Accessed on: 26.ix.2019.

Wahl, D. B. (1993). Cladistics of the ichneumonid subfamily Labeninae (Hymenoptera: Ichneumonidae). Entomologia Generalis, 18: 91105. doi: 10.1127/entom.gen/18/1993/91

Yu, D. S.; van Achterberg, C.; Horstmann, K. (2016). Taxapad 2016. Ichneumonoidea 2015 (Biological and taxonomical information), Taxapad Interactive Catalogue Database on flash-drive. Nepean, Ottawa, Canada. 